\title{
TRATAMENTO DIFERENCIADO ÀS MICROEMPRESAS E EMPRESAS DE PEQUENO PORTE EM PREGÕES ELETRÔNICOS: O CASO DA UNIVERSIDADE FEDERAL DE LAVRAS
}

Gisele Costa ${ }^{1}$

Fabiane Fidelis Querino $^{2}$

Leandro Rivelli Teixeira Nogueira ${ }^{1}$

Maria Aparecida Curi ${ }^{1}$

\footnotetext{
${ }^{1}$ Universidade Federal de Alfenas

${ }^{2}$ Universidade Federal de Lavras
} 


\section{TRATAMENTO DIFERENCIADO ÀS MICROEMPRESAS E EMPRESAS DE PEQUENO PORTE EM PREGÕES ELETRÔNICOS: O CASO DA UNIVERSIDADE FEDERAL DE LAVRAS}

Resumo: Esse estudo tem como objetivo analisar os pregões eletrônicos da UFLA entre os anos de 2012 a 2015, a fim de descrever como ocorreu na prática a aplicação do tratamento diferenciado às MPEs. Foi realizada entrevista com os servidores da Diretoria de Gestão de Materiais, visando a colher informações sobre a percepção dos mesmos a respeito dessa política pública para a UFLA. No Portal de Compras do Governo Federal, foram obtidos dados referentes aos processos licitatórios da universidade no período de 2012 a 2015 . Evidenciou-se a falta de adaptação dos sistemas de informação para operacionalização das mudanças e uma preocupação em não conseguir alcançar o objetivo de efetivar a aquisição de bens ou adquirilos por valores elevados. Por outro lado, identificou-se que os pregoeiros reconhecem na Lei a importância do fomento aos pequenos negócios e foi demonstrado que houve aumento de valores pagos pela administração a partir de sua aplicação.

Palavras-chave: Licitações. Micro e pequenas empresas. Tratamento diferenciado. Pregões.

\section{$1 \quad$ Introdução}

Estudo do Serviço Brasileiro de Apoio às Micro e Pequenas Empresas (SEBRAE, 2013a) indica que 99\% dos estabelecimentos em funcionamento no Brasil são classificados como micro e pequenas empresas (MPEs), nelas se concentram 52\% dos empregos formais de estabelecimentos privados não agrícolas e quase $42 \%$ da massa de salários paga aos trabalhadores desses estabelecimentos. Os números do estudo oferecem a dimensão da importância social e econômica que a categoria assume ao representar a maioria das empresas estabelecidas no país e gerar o maior número de empregos.

Apesar da ampla participação na economia, as MPEs enfrentam dificuldades para se estabelecerem. Cabral, Reis e Sampaio (2015) ressaltam que, se por um lado as MPEs possuem processos decisórios mais rápidos, por outro têm que lidar com maiores restrições relacionadas à escala de operações, o que pode fazer com que estejam excluídas do processo competitivo.

Visando a minimizar a disparidade existente entre as MPEs e as grandes empresas, o governo tem instituído políticas públicas que conferem certos benefícios aos pequenos negócios. Tais políticas têm sua afirmação na importância que a categoria assume para a economia do país e contemplam, dentre outros benefícios, redução de obrigatoriedades nos processos licitatórios da administração pública.

O tratamento diferenciado a ser dispensado às MPEs por parte da União, Estados, Distrito Federal e Municípios está previsto na Constituição Federal de 1988 (BRASIL, 1988). Tal preceito foi inserido no ordenamento jurídico com o objetivo de imprimir justiça às relações das MPEs com o mercado, considerando ser improvável que os pequenos negócios com sua estrutura fragilizada se estabeleçam diante da alta carga tributária e demais exigências do mercado (SEBRAE, 2013a).

A Lei Complementar $n^{\circ} 123$, de 14 de dezembro de 2006 (BRASIL, 2006) foi instituída para regulamentar o disposto na $\mathrm{CF} / 88$ e instituiu o regime tributário específico, denominado 
Simples Nacional que, dentre outros benefícios, propiciou maior facilidade de acesso ao mercado para as MPEs, inclusive o de compras governamentais. Em agosto de 2014, houve a aprovação da Lei Complementar $n^{\circ} 147 / 2014$, que reforçou alguns critérios de tratamento diferenciado às MPEs, com a obrigatoriedade de aplicação irrestrita por parte dos órgãos públicos.

A partir da publicação da Lei no 147/2014 (BRASIL, 2014a) o tratamento diferenciado às MPEs passou a ser imperativo, deixando de ser uma ação discricionária do agente público. A atuação dos órgãos da administração pública em relação a essa mudança tem sido objeto de estudo de alguns trabalhos recentes, o que inspirou a elaboração deste trabalho que tem como foco o tratamento dispensado às MPEs por parte da Universidade Federal de Lavras - UFLA em seus pregões eletrônicos.

Para o desempenho de sua missão e manutenção de suas atividades a UFLA deve realizar suas compras de acordo com os preceitos da Lei $n^{\circ}$ 8.666/93 (BRASIL, 1993) que institui normas para licitações e contratos da Administração Pública e demais legislações que regulamentam as aquisições do Setor Público, dentre elas as que dispõem sobre como o governo deve comprar das MPEs. Considerando a obrigatoriedade imposta pelas alterações instituídas pela Lei Complementar $n^{\circ}$ 147/2014 para que se ofereça tratamento diferenciado que concede benefícios às MPEs, a questão que se coloca é como está ocorrendo a aplicação dessa política pública nos processos licitatórios da UFLA?

Tendo ciência da importância das MPEs para o desenvolvimento econômico e social do país bem como para a geração de emprego e renda, e entendendo-se que as recentes Políticas Públicas, no Brasil, visam a ampliar a participação destas nas transações com os entes governamentais, conduziu-se este estudo com o objetivo geral de é descrever como ocorreu na prática da instituição, a aplicação do tratamento diferenciado às MPEs, conforme disposto pela Lei Complementar $n^{\circ}$ 123/2006 (BRASIL, 2006).

Para tratar do assunto proposto, fez-se uma breve abordagem sobre as características gerais das compras no setor público e de que forma ocorre a participação das micros e pequenas empresas nas compras públicas. Seguindo-se da apresentados e discutidos os resultados encontrados e apresentada uma proposta de intervenção, visando a melhoria no fluxo dos processos licitatórios que devam atender às disposições da Lei $\mathrm{n}^{\circ}$ 123/2006 e encerrando com a conclusão.

\section{Referencial Teórico}

\subsection{Compras no Setor Público}

O Poder Público não dispõe de ampla liberdade como os particulares quando pretende adquirir, alienar, locar bens, contratar obras ou serviços. Para executar tais ações, o Poder Público deve adotar procedimento preestabelecido na conformidade da lei, sendo tal procedimento denominado licitação (MELLO, 2015).

A licitação encontra sua previsão legal na Constituição Federal de 1988 (CF/88), inciso XXI do art. 37, pautando-se no reconhecimento da importância do uso eficiente dos recursos públicos, obrigando que as obras, serviços, compras e alienações públicas sejam feitas por meio de processo licitatório, assegurando igualdade de condições a todos os concorrentes (BRASIL, 1988, p. 42). 
A licitação foi regulamentada pela Lei Federal $n^{\circ} 8.666$, de 21 de junho de 1993, atualizada pela Lei ${ }^{\circ} 8.883$, de 8 de junho de 1994, Lei $n^{\circ} 9.648$, de 27 de maio de 1998 e pela Lei $\mathrm{n}^{\circ}$ 9.854, de 27 de outubro de 1999. A Lei $\mathrm{n}^{\circ}$ 8.666/1993 é a veiculadora das normas gerais obrigatórias em todo o país, considerando ainda, as alterações que lhe foram introduzidas por medidas provisórias e leis.

Estados, Distrito Federal e Municípios podem legislar sobre licitação em sua esfera específica, porém todos devem acatar as normas gerais editadas pela União. Tanto a Administração direta quanto as autarquias, fundações públicas, empresas públicas, sociedades de economia mista e demais entidades controladas direta ou indiretamente pela União, Estados, Distrito Federal e Municípios devem atuar em conformidade com as normas editadas pela União (MEIRELLES, 2015).

Licitação requer disputa, concorrência, portanto, somente são licitáveis objetos que possam ser fornecidos por mais de uma pessoa. Em razão de uma diversidade de hipóteses em que não seja possível a licitação, a Lei 8.666/1993 prevê casos de dispensa de licitação e inexigibilidade.

Esse estudo apresentará a Lei $\mathrm{n}^{\circ} 123 / 2006$ que trata de uma lei criada para conceder às microempresas e empresas de pequeno porte tratamento diferenciado quanto à forma de tributação e em outras áreas como, por exemplo, o acesso ao mercado das compras públicas, foco desse trabalho.

\subsection{Política Pública em Favor das MPES}

No Brasil, o movimento pela valorização das pequenas empresas despontou mais fortemente a partir dos anos 80, enquanto que em países mais desenvolvidos, a exemplo dos Estados Unidos, o movimento data da década de 50 (SACHS, 2008). O marco brasileiro foi a inclusão dos artigos 170 e 179 na Constituição Federal de 1988 (BRASIL, 1988), instituindo que a União, Estados, Distrito Federal e Municípios deveriam dispensar às MPEs, tratamento jurídico diferenciado e favorecido, visando a incentivá-las pela simplificação, eliminação ou redução de suas obrigações administrativas, tributárias, previdenciárias e creditícias. O texto constitucional reservou tratamento diferenciado como forma de incentivo às MPEs a fim de que se estabelecesse um cenário mais justo que contribuísse para sua sobrevivência no mercado.

Apesar da previsão constitucional, durante algum tempo registraram-se tentativas de se estabelecer uma efetiva regulamentação que transformasse o disposto em prática, permanecia, porém, uma distância entre o estabelecido nos projetos de lei e o que efetivamente era pleiteado pelo setor. Nesse período, grupos de interesse em defesa das MPEs atuaram de forma a pressionar o Estado e suas políticas públicas em prol da categoria. Muitos projetos de lei e propostas estiveram em discussão, alguns foram aprovados, receberam modificações e, finalmente, no ano de 2006 foi aprovada a Lei Complementar ${ }^{\circ}$ 123/2006, conhecida como Lei Geral ou Estatuto da Microempresa. Tal instrumento legal compreende uma série de ações que, notadamente os órgãos governamentais, passaram a adotar em prol da categoria (SEBRAE, 2013a).

A Lei Geral das Microempresas e Empresas de Pequeno Porte instituída em 2006 regulamentou o disposto na Constituição Federal de 1988 (BRASIL, 1988) e representou um marco de conquista para o setor. Instituiu o regime tributário específico, denominado Simples Nacional para os pequenos negócios, com redução da carga de impostos e simplificação dos processos de cálculo e recolhimento. Além disso, promoveu simplificação e desburocratização, 
maior facilidade para acesso ao mercado, ao crédito e o estímulo à inovação e à exportação (BRASIL, 2006).

As alterações pelas quais passou a Lei Complementar $n^{\circ} 123 / 2006$, podem ampliar a possibilidade das MPEs obterem sucesso nas compras governamentais. A ampliação de prazos para regularização da documentação, e exclusividade concedida, a reserva obrigatória de cotas nos processos licitatórios, são medidas que visam a atenuar ainda mais as dificuldades enfrentadas pelas MPEs para que tenham reais chances de usufruírem do potencial mercado que as compras públicas representam.

\section{Metodologia}

Baseado em Gil (2014), a abordagem adotada neste estudo teve a finalidade descritiva e exploratória. A intenção foi descrever como ocorreu na prática da instituição, a aplicação do tratamento diferenciado às MPEs, conforme disposto pela Lei Complementar $n^{\circ} 123 / 2006$.

$\mathrm{O}$ caráter exploratório da pesquisa diz respeito à descoberta a que ela se propõe. Segundo Baptista e Campos (2007) observam que, por meio das ações da análise exploratória, são explicitadas informações subjacentes ao fenômeno estudado.

Por meio da abordagem escolhida, houve a descrição do procedimento adotado pela Diretoria de Gestão de Materiais da UFLA, considerando as mudanças ocorridas após a publicação da Lei Complementar $n^{\circ}$ 147/2014 e a análise de alguns dos efeitos advindos da aplicação dos critérios da Lei.

Foram coletados dados primários por meio de entrevista pessoal com base em roteiro, aos servidores da Diretoria de Gestão de Materiais que atuam como pregoeiros nos processos licitatórios.

Foi escolhido o modelo de entrevista semiestruturada, que segundo Kerlinger (2009), oferece aos entrevistados liberdade para acrescentar pontos que considerassem relevantes, apesar de haver um roteiro prévio.

A fim de preservar a identidade dos entrevistados, os servidores que atuam como pregoeiros, na Diretoria de Gestão de Materiais, foram designados por P1, P2, P3, P4 e P5.

Conforme Baptista e Campos (2007), a pesquisa documental restringe-se à utilização de fontes primárias de informação como documentos, censos, contratos etc.

Foram levantados dados de fontes documentais da Universidade Federal de Lavras, especificamente da Diretoria de Gestão de Materiais - DGM, e também dados disponíveis no Portal de Compras do Governo Federal (Comprasnet) que dizem respeito a editais, atas e outros documentos que compõem os processos de aquisições de materiais e serviços no período de 2012 a 2015. A delimitação desse período se deu em razão de o mesmo compreender um período anterior e um posterior à publicação da Lei Complementar $n^{\circ} 147 / 2014$ que trouxe obrigatoriedades anteriormente não consideradas pela Lei Complementar no 123/2006.

A técnica utilizada para análise das entrevistas com os servidores da UFLA foi a análise de conteúdo. A partir do resultado da análise de conteúdo, traçaram-se eixos principais de percepção dos pregoeiros em relação à adoção dos critérios que conferem tratamento diferenciado às MPEs. Para algumas questões apontadas nos posicionamentos dos pregoeiros como efeitos da aplicação da legislação houve, então, análises quantitativas pontuais que visaram a confirmar ou não sua ocorrência. 
Para organizar os dados coletados por meio da pesquisa documental dos processos licitatórios, foi utilizada a análise de frequência. Por meio de distribuição de frequência, os dados foram agrupados e resumidos em tabelas e gráficos. Tratou-se de uma análise exploratória de dados.

A fim de apontar a variação no número de MPEs participantes e/ou vencedoras nos pregões eletrônicos que ocorreram no período de 2012 a 2015, foi realizada a análise de cada edital publicado. Foi examinada a declaração de porte das empresas que participaram e a partir dessa informação foi possível elaborar um quadro com a quantidade de MPEs que participaram dos pregões e que foram vencedoras de pelo menos um item. $\mathrm{O}$ resultado foi expresso em valores percentuais a fim de tornar a informação mais clara ao leitor.

\section{Resultados e Discussões}

\subsection{Percepção dos servidores}

Por meio de entrevista com roteiro semiestruturado, pôde-se verificar qual a percepção dos pregoeiros em relação aos procedimentos a serem adotados em atendimento às obrigatoriedades que a Lei Complementar $n^{\circ} 147 / 2014$ incorporou à Lei Complementar $n^{\circ}$ 123/2006. Foi possível identificar elementos que auxiliaram na análise do contexto administrativo, considerando o fluxo de processo existente, que trouxe subsídios para a sugestão de melhorias no processo.

A análise de conteúdo das entrevistas permitiu identificar três eixos principais em torno dos questionamentos apresentados, que foram os seguintes: (A) fomento ao desenvolvimento e a competitividade; (B) maior complexidade dos processos licitatórios; (C) alterações e adaptações necessárias.

Eixo A - fomento ao desenvolvimento e a competitividade. Os pregoeiros entrevistados demonstraram considerar como principal ponto positivo da Lei o objetivo que ela traz de fomentar a atividade dos pequenos negócios. Segue trechos das entrevistas:

O benefício às micro e pequenas empresas surge como uma forma de o governo, com seu poder de compra e do potencial social que tem, promover o desenvolvimento econômico e social do país. [...] a Lei, pelos propósitos e finalidade que almeja alcançar deve ser louvada. (P1)

Vejo que o governo quer facilitar a participação do empresário de pequeno porte e do microempresário nas licitações [...]. Com isso, o governo promove política de desenvolvimento e incentivo à microempresa e à empresa de pequeno porte. (P5)

No eixo A, de análise, evidenciou-se o conhecimento e a concordância dos pregoeiros com o objetivo da Lei de propiciar condições mais favoráveis às MPEs, para que participem das licitações promovidas pelos órgãos públicos. Houve menção também à questão do incentivo ao desenvolvimento econômico e/ou social que a Lei propicia. Percebe-se, nesta análise, que os pregoeiros reconhecem a situação de desigualdade das MPEs ao concorrer com empresas de médio e grande portes nas licitações.

Eixo B - maior complexidade dos processos licitatórios. Os pregoeiros entrevistados deixaram claro em suas falas que as principais alterações ocorridas nos seus processos de trabalho, após a alteração da Lei foram: a) nos pregões cujo valor estimado é de até $\mathrm{R} \$$ 80.000,00 (oitenta mil reais), passou a haver participação exclusiva de MPEs (aplicação do benefício tipo I); b) nos pregões cujo valor estimado supere $\mathrm{R} \$ 80.000,00$ (oitenta mil reais), nos itens que forem divisíveis, passou a haver a necessidade de dividir o quantitativo, restringindo uma cota de até $25 \%$ para as MPEs, sendo o restante do quantitativo destinado a 
ampla concorrência (benefício tipo III) e c) na fase de habilitação do certame, havendo irregularidade fiscal na documentação das MPEs, passou a ser concedido um prazo de cinco dias úteis para a regularização da situação, podendo este ser prorrogado por igual período. Seguem trechos relevantes das entrevistas, que tocaram nessas questões:

O sistema Comprasnet não está adaptado, em seu módulo de Registro de Preços, para a aplicação do benefício tipo III e, sendo assim, a aplicação deste tipo de benefício tem de ser feita de forma manual. (P1)

Em algumas situações pagamos mais caro pelo item para a microempresa, porque ela compra das grandes empresas para nos vender e outras vezes nem conseguimos comprar o item porque as microempresas não conseguem fornecer ao nosso valor estimado que pode ter sido balizado em preços de mercado que as grandes empresas atendem. (P2)

As microempresas não dispõem de capacidade produtiva como as grandes empresas, não tendo como competir em pé de igualdade com estas grandes, principalmente quando se trata de preços. Essa situação leva a um encarecimento das compras públicas. (P1)

Os problemas apontados com unanimidade pelos pregoeiros tratam da falta de adaptação dos sistemas de informação, tanto do governo (Comprasnet) quanto interno (SIPAC) onde são divulgados e executados os pregões e ao alto custo de aquisição de alguns itens. Outro problema apontado foi a questão do risco de haver compra de itens sem padronização em função da divisão de um mesmo item em cotas que podem ser vencidas por fornecedores diferentes.

Eixo C - alterações e adaptações necessárias. Os pregoeiros entrevistados foram unânimes em considerar como principais pontos para melhorar a aplicação da Lei, a adaptação dos sistemas de informação para trazer agilidade ao processo de trabalho e a possibilidade de não aplicação do benefício de reserva de cotas de $25 \%$ para MPEs ou que esta reserva seja facultativa para itens de valor superior a $\mathrm{R} \$ 80.000 .00$, quando divisíveis. Essa última adaptação, entretanto, depende de nova mudança na legislação, o que impede, por ora, sua adoção. Os trechos que seguem demonstram o posicionamento:

Uma medida seria o Governo Federal exigir que os sistemas de informação para compras públicas estejam totalmente aptos para atender à legislação antes dela entrar em vigor, ou caso já esteja em vigência que exista um tempo para adaptação. (P2)

Aponto a necessidade do Comprasnet se adequar para sua operacionalização. (P3)

O conteúdo das entrevistas evidenciou que, apesar de todos os pregoeiros entrevistados reconhecerem como ponto positivo da Lei o fomento aos pequenos negócios, há um receio de que os benefícios concedidos às MPEs resultem no insucesso do processo de compra. A percepção dos pregoeiros é de que ocorrerão maior número de itens que não serão adquiridos ou ocorrerá valores de compra mais altos para a administração, dentre outros problemas, como aumento da morosidade dos processos licitatórios e aquisição de itens sem padronização.

\subsection{Análise dos processos licitatórios da UFLA entre os anos de 2012 a 2015}

Ao analisar os processos licitatórios da UFLA, identificou-se que a população inicial se constituía de 494 pregões eletrônicos entre os anos de 2012 a 2015. Após a análise do objeto e do resultado dos pregões, foram excluídos aqueles que, por ventura, foram cancelados ou revogados, ou seja, os que não tiveram vencedores do certame. Finalizado esse tratamento inicial, prosseguiu-se com uma população de 484 pregões eletrônicos para a realização do estudo. 
$\mathrm{Na}$ Tabela 1, mostra-se a quantidade de pregões realizados de 2012 a 2015 . Houve diminuição no número de pregões no decorrer dos anos, em relação ao ano de 2012, porém cresceu o montante do valor homologado.

Tabela 1: Número de Pregões realizados pela UFLA e respectivos valores entre 2012 e 2015.

\begin{tabular}{lcc}
\hline Ano & Número de pregões & Valor homologado (R \$ milhões) \\
\hline 2012 & 139 & $\mathbf{3 6 , 1 4}$ \\
2013 & 137 & $\mathbf{6 3 , 9 6}$ \\
2014 & 101 & $\mathbf{5 9 , 5 7}$ \\
2015 & 107 & $\mathbf{5 6 , 0 8}$ \\
\hline
\end{tabular}

Fonte: Dados da pesquisa (2016).

Com a finalidade de apresentar um panorama geral sobre a participação das MPEs nos processos licitatórios da UFLA, especificamente na modalidade pregão eletrônico, apresentamse, na Tabela 2, os números dessa participação no período de 2012 a 2015, conforme apurado por meio das atas dos pregões eletrônicos disponíveis no Portal de Compras do Governo Federal (Comprasnet).

Tabela 1 - Participação de MPEs nos pregões da UFLA entre 2012 e 2015.

\begin{tabular}{|c|c|c|c|c|}
\hline Ano & $\begin{array}{l}\text { Número de MPEs } \\
\text { participantes }\end{array}$ & 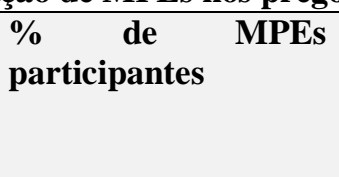 & $\begin{array}{l}\text { Número de MPEs } \\
\text { que venceram pelo } \\
\text { menos } 1 \text { item }\end{array}$ & $\begin{array}{ll}\text { \% de MPEs } & \text { das } \\
\text { empresas } & \text { que } \\
\text { venceram } & \text { pelo } \\
\text { menos } 1 \text { item } & \end{array}$ \\
\hline 2012 & 1324 & $86 \%$ & 514 & $86 \%$ \\
\hline 2013 & 1511 & $85 \%$ & 581 & $84 \%$ \\
\hline 2014 & 1163 & $92 \%$ & 404 & $95 \%$ \\
\hline 2015 & 1175 & $92 \%$ & 345 & $96 \%$ \\
\hline
\end{tabular}

Fonte: Dados da pesquisa (2016).

Conforme Tabela 2, os dados apresentados demonstram um crescimento percentual da participação de MPEs nos pregões da UFLA, a partir do ano de 2014, em relação ao total de empresas participantes. Esse aumento ocorreu quanto ao número de MPEs que participaram, quanto ao número de MPEs que efetivamente venceram pelo menos um item e quanto ao número total de itens homologados para MPEs.

Em relação ao valor total das compras realizadas, por meio de pregão, não se observou aumento no percentual homologado para as MPEs, conforme apresentado na Tabela 3. Na Tabela, apresenta-se na segunda e terceira colunas, a quantidade e respectivo percentual de itens cuja venda se realizou por MPEs. A quarta coluna apresenta o montante em valores anuais dos itens fornecidos por MPEs e a quinta coluna apresenta o valor em percentual das compras realizadas de MPEs em relação ao valor total das compras anuais do órgão. Apesar do aumento percentual do número de MPEs vencedoras e de itens homologados para estas, apenas de 2012 para 2013 houve ampliação dos valores homologados para MPEs. Nos demais anos em termos de valores não houve crescimento.

Tabela 2 - Números da participação de MPEs nos pregões eletrônicos de 2012 a 2015. 


\begin{tabular}{|c|c|c|c|c|}
\hline Ano & $\begin{array}{l}\text { Número de } \text { itens } \\
\text { vencidos por } \\
\text { MPEs }\end{array}$ & $\begin{array}{ll}\% \quad \text { de } & \text { itens } \\
\text { homologados } & \\
\text { vencidos } & \text { por } \\
\text { MPEs } & \\
\end{array}$ & $\begin{array}{l}\text { Valor das compras de } \\
\text { MPEs }(\mathbf{R} \$)\end{array}$ & $\begin{array}{l}\% \text { do valor total } \\
\text { das compras } \\
\text { homologadas }\end{array}$ \\
\hline 22012 & 6432 & $82 \%$ & 14.971.818,46 & $41 \%$ \\
\hline 22013 & 4591 & $86 \%$ & 46.332.427,74 & $72 \%$ \\
\hline 22014 & 3197 & $97 \%$ & 40.603.910,53 & $68 \%$ \\
\hline 22015 & 3016 & $99 \%$ & 40.705.092,98 & $72 \%$ \\
\hline
\end{tabular}

Fonte: Dados da pesquisa (2016).

Nos dados da Tabela 3, demonstra-se que os itens vencidos por empresas de médio e grande porte, apesar de serem em menor número, representam um percentual maior do valor das aquisições da UFLA. Supostamente, esse quadro se explica pela maior capacidade das empresas de médio e grande porte em fornecer produtos com maior valor agregado. Nota-se que, por exemplo, no ano de 2015, 99\% dos itens foram homologados para MPEs, o que em valores correspondeu a $72 \%$ do montante das compras, o que quer dizer que apenas $1 \%$ do que foi vendido por empresas de médio e grande porte alcançou $28 \%$ do montante em valores.

Cabral, Reis e Sampaio (2015), em trabalho que analisa a participação de MPEs nos pregões da Fundação Oswaldo Cruz (Fiocruz) na Bahia testou a hipótese de que quanto maiores os montantes financeiros envolvidos, menores as chances de as MPEs participarem e vencerem processos de compras públicas. Os resultados indicaram que, controlando os outros fatores, a probabilidade de participação de MPE nos pregões eletrônicos, contemplados na análise, é reduzida significativamente $(p<0,5$ e 0,01$)$ com o aumento no valor dos contratos. Para Wales et al. (2013), a ausência de competências de empresas de pequeno porte tende a estar correlacionada com desempenho insatisfatório. O resultado do estudo realizado na Fiocruz apresenta consonância com as informações obtidas e apresentadas na Tabela 3, na medida em que demonstra que as MPEs geralmente vencem itens com menor valor agregado.

\subsection{Aplicação do tratamento diferenciado às MPES na UFLA entre 2012 e 2015}

Considerando a Lei $\mathrm{n}^{\circ}$ 123/2006 e a partir da metodologia adotada no estudo, foi realizada uma análise de como ocorreu a aplicação de cada disposição legal que concede tratamento diferenciado às MPEs, no âmbito da Diretoria de Gestão de Materiais da UFLA no período de 2012 a 2015.

\subsubsection{Prazo para Regularidade Fiscal}

Após as alterações ocorridas na Lei Complementar n 123/2006, após a publicação da Lei Complementar $n^{\circ}$ 247/2014, houve ampliação do prazo para apresentação de regularidade fiscal por parte das MPEs. O prazo que se inicia a partir do momento em que o proponente for declarado vencedor, anteriormente era de dois dias úteis e com a mudança da Lei passou a ser de cinco dias úteis. Ressalta-se que as MPEs não podem simplesmente não apresentar os documentos solicitados no instrumento convocatório, mas deverão apresentar o documento fiscal vencido para garantir a participação no certamente e, então, terão concedido o prazo previsto de cinco dias prorrogáveis por igual período para a regularização.

$\mathrm{O}$ estudo apontou, por meio das mensagens obtidas nos chats entre pregoeiros e fornecedores e disponíveis no Comprasnet, que na UFLA, a concessão de prazo para regularização fiscal foi observada durante o período de 2012 a 2015. O prazo de dois dias passou a ser de cinco dias, após as alterações ocorridas em agosto de 2014. A prorrogação aconteceu poucas vezes e levou em consideração os motivos pelas quais a empresa não conseguiu regularizar sua situação, as condições da próxima licitante, entre outras. Não se observou o 
estabelecimento de um critério rígido, a aplicação ocorreu de maneira situacional, sustentandose no entendimento de que a decisão de prorrogar é discricionária da administração.

\subsubsection{Licitação Exclusiva}

Após as alterações trazidas pela Lei Complementar no 147/2014, o artigo 48 da Lei Complementar $n^{\circ}$ 123/2006 passou a dispor que a administração pública deverá realizar processo licitatório destinado exclusivamente à participação de MPEs nos itens de contratação cujo valor seja de até $\mathrm{R} \$ 80.000,00$ (oitenta mil reais). Anteriormente, tal ato era uma possibilidade da administração pública que discricionariamente decidia ou não pela sua aplicação.

O estudo revelou a utilização do critério de exclusividade pela primeira vez na UFLA, considerando a delimitação de tempo da pesquisa, no pregão $\mathrm{n}^{\circ} 17 / 2014$ realizado em 09/10/2014. A aplicação desse benefício ocorre, portanto, somente após a publicação da Lei Complementar $\mathrm{n}^{\text {o }} 147 / 2014$ de 07/08/2014, ou seja, após a exclusividade ser obrigatória, por força da Lei.

No Gráfico 1, apresenta-se o percentual de itens destinados exclusivamente para MPEs nos processos licitatórios do período em análise.

\section{Gráfico 1 - Percentual de itens destinados exclusivamente para MPEs de2012 a 2015.}

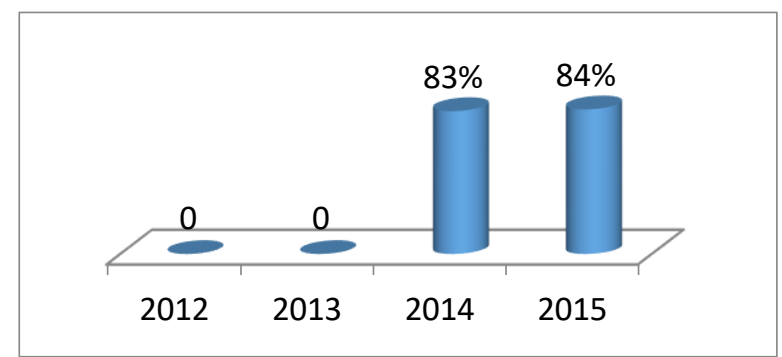

Fonte: Dados da pesquisa (2016).

Nota-se que anteriormente à alteração da Lei Complementar n 123/2006, a UFLA não praticava a prerrogativa legal de destinar a licitação de itens de valor até $\mathrm{R} \$ 80.000,00$ (oitenta mil reais) exclusivamente às MPEs. A partir da obrigatoriedade imposta pela Lei e anteriormente à publicação do Decreto $\mathrm{n}^{\mathrm{o}}$ 8.538/2015 que regulamentou as alterações, a instituição passou a adotar o disposto em todos os seus pregões. Desde então, os itens licitados na modalidade de pregão eletrônico, destinados exclusivamente às MPEs tem superado o percentual de $80 \%$ (oitenta por cento) do total de itens, ou seja, dos itens licitados, em média $20 \%$ (vinte por cento) apresentam valores superiores a $\mathrm{R} \$ 80.000 .00$ (oitenta mil reais).

Diante da constatação do expressivo número de itens destinados com exclusividade às MPEs, o estudo expôs uma questão relacionada ao percentual de itens que a universidade não conseguiu adquirir por meio dos pregões. A partir dos dados coletados, procurou- se observar se a concessão de exclusividade de grande parte dos itens às MPEs fora acompanhada de aumento no percentual de itens não adquiridos, uma vez que, aventa-se a hipótese de que a restrição na possibilidade de participação de empresas de outros portes pudesse ter reduzido a competitividade por alguns itens.

No Gráfico 2, é apresentado o percentual de itens não adquiridos no período considerado para o estudo. Cabe esclarecer que os itens não são adquiridos quando a oferta não satisfaz algum critério estabelecido no edital ou quando esta ocorre por valores acima do valor de 
referência adotado pelo órgão. Nesses casos, os itens são cancelados na fase do pregão chamada de "aceitação", ou seja, são cancelados na aceitação. Outra razão que causa insucesso na aquisição dos itens em licitação é a inexistência de propostas, ou seja, não surge nenhuma empresa interessada e disposta a oferecer lance para aquisição de determinados itens, nesse caso, a licitação é considerada "deserta".

Gráfico 2 - Percentual anual de itens não adquiridos nos pregões realizados.

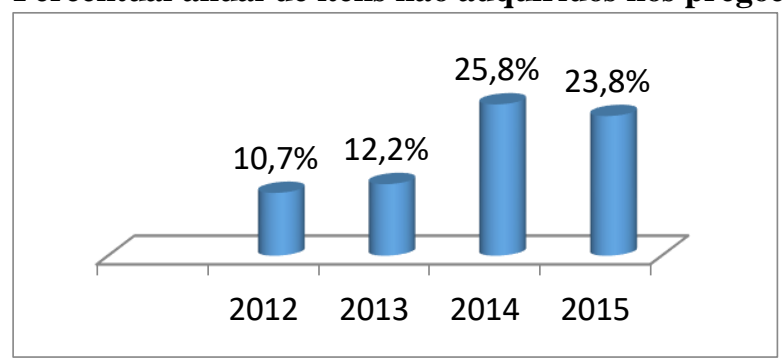

Fonte: Dados da pesquisa (2016).

É possível constatar, a partir dos percentuais apresentados no gráfico 2 que houve considerável aumento no número de itens não adquiridos pela UFLA em seus pregões a partir do ano de 2014. Considerando as alterações adotadas nos processos licitatórios, no sentido de atender as mudanças na legislação, reforça-se a hipótese de que a destinação de um considerável percentual de itens para participação exclusiva de MPEs pode ter ocasionado insucesso nas aquisições. As MPEs participantes não conseguiram fornecer parte dos itens de acordo com os critérios estabelecidos pelos editais ou não conseguiram oferecê-los até o limite do valor de referência adotado para aceitação.

Visando a aprofundar as informações a respeito desse cenário, o estudo analisou cada item não adquirido e percebeu-se que como principal causa do insucesso na aquisição, está o valor elevado pelo qual as empresas se dispõem a fornecer os itens. Notaram-se valores acima dos valores de referência adotados pela Diretoria de Gestão de Materiais, que são calculados com base nas pesquisas de preço realizadas.

Dados obtidos no portal Comprasnet e apresentados na Tabela 4 demonstram o percentual de itens não aceitos, por porte de empresa e, portanto cancelados, entre 2012 e 2015.

Tabela 3 - Percentual de itens não aceitos, por porte de empresa, de 2012 a 2015

\begin{tabular}{ccc}
\hline & MPEs & Outras \\
\hline 2012 & $94,6 \%$ & $\mathbf{5 , 4 \%}$ \\
2013 & $95,4 \%$ & $\mathbf{4 , 6 \%}$ \\
2014 & $99,7 \%$ & $\mathbf{0 , 3 \%}$ \\
2015 & $\mathbf{9 9 , 4 \%}$ & $\mathbf{0 , 6 \%}$ \\
\hline
\end{tabular}

Fonte: Dados da pesquisa (2016).

Conforme informações apresentadas na Tabela 4, quase a totalidade dos itens que a universidade não conseguiu adquirir nos processos licitatórios entre 2012 e 2015 foi proveniente de ofertas não aceitáveis de MPEs. Tal cenário se explica pela maior participação das empresas de pequeno porte, porém, é nítida uma situação de incapacidade das MPEs em ofertar os itens dentro dos valores de referência ou das especificações exigidas.

Além dos itens cancelados na aceitação, existiram ainda numerosos cancelamentos em virtude da inexistência de proposta, ou seja, não houve capacidade ou não houve interesse por parte das MPEs em fornecer, considerando o preço de referência e as especificações exigidas. 
No Gráfico 3, as informações são consolidadas e demonstram o percentual de itens adquiridos, o percentual de itens para os quais não houve proposta e o percentual de itens cancelados na aceitação. Esse último grupo, representa itens ofertados em desacordo com o especificado ou por valores acima do valor de referência.

Gráfico 3 - Itens homologados, cancelados por inexistência de proposta e cancelados na aceitação.

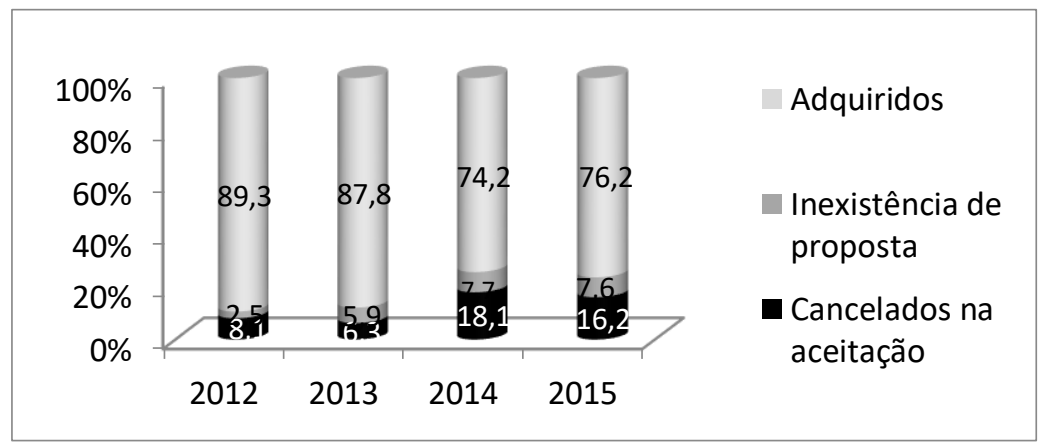

Fonte: Dados da pesquisa (2016).

Diante dos resultados, percebe-se que atenção especial deve ser dada a essa situação, pois devendo atender à exigência legal de conceder exclusividade às MPEs na oferta de itens, a administração deve estar ciente de um possível aumento no número de itens não adquiridos, conforme demonstrou o resultado do estudo. Adiante, o estudo apresentará sugestão de melhoria no fluxo do processo licitatório, como medida que pode vir a contribuir para amenizar a chance de insucesso nas aquisições.

\subsubsection{Subcontratação}

Após a alteração na Lei Complementar no 123/2016, no artigo 48, inciso II, a possibilidade de exigir dos licitantes a subcontratação de MPEs deixou de ser limitada a 30\% do total licitado. Para este estudo buscou-se conhecer se a UFLA adota a subcontratação em seus processos e se houve mudança com a alteração da Lei. Essa possibilidade se destina aos processos licitatórios para aquisição de obras e serviços e trata-se de uma opção que a administração pode fazer, não havendo, portanto, obrigatoriedade.

Foi constatado que a UFLA não tem adotado a subcontratação nos processos de contratação de obras e serviços. Houve casos específicos de editais que permitiram subcontratação, porém de forma isolada em atividades acessórias. Nesse caso, portanto, a mudança na legislação não trouxe nenhuma alteração para o processo de trabalho.

\subsubsection{Cota Reservada}

O estudo demonstrou que para atender à disposição que prevê a reserva de cota de $25 \%$ dos itens divisíveis de valor superior a $\mathrm{R} \$ 80.000 .00$ (oitenta mil reais) para as MPEs, é necessária a duplicação do item no edital do processo licitatório. Tal procedimento gera retrabalho e é um inconveniente operacional que ocorre em virtude do sistema disponibilizado pelo governo não estar adaptado para esse desdobramento.

Esse cenário acabou por influenciar a UFLA a adotar timidamente essa disposição legal durante o período em análise. Constatou-se que a aplicação desse benefício ocorreu pela primeira vez no pregão $n^{\circ} 114 / 2014$ realizado em 10/12/2014. No ano de 2015, a reserva de cota foi aplicada em apenas dois pregões e somente a partir do ano de 2016, a aplicação desse benefício começou a ocorrer com maior frequência. 
Ressalta-se que o Decreto $\mathrm{n}^{\mathrm{o}} 8.538 / 2015$ de 06 de outubro de 2015 (BRASIL, 2015), que regulamentou o tratamento favorecido, diferenciado e simplificado para as MPEs passou a vigorar a partir de 06/01/2016, o que explica a maior frequência na aplicação do benefício de reserva de cota de $25 \%$ dos itens divisíveis de valor superior a $\mathrm{R} \$ 80.000 .00$ (oitenta mil reais) a partir do ano de 2016.

\subsubsection{Dispensas por Valor e Inexigibilidade}

Anteriormente à alteração da Lei Complementar n ${ }^{\circ}$ 123/2006, para os casos de dispensa de licitação e inexigibilidade, previstas pelos artigos 24 e 25 da Lei ${ }^{\circ}$ 8.666/1993, não se aplicava o tratamento diferenciado às MPEs. Após a alteração, para os casos de dispensa de licitação e inexigibilidade contempladas pelos citados artigos, a Lei passou a dispor que se devem adquirir os materiais ou serviços preferencialmente de MPEs.

Em análise aos processos de dispensa de licitação e inexigibilidade da UFLA, no período do estudo, não se observou a existência de uma ação da Diretoria da Gestão de Materiais no sentido de conceder preferência às MPEs. Apesar disso, os resultados dos processos licitatórios demonstraram alto percentual de itens vencidos por MPEs em todos os anos analisados. Não pode se afirmar, portanto, que a alteração na legislação trouxe algum efeito a tal procedimento na UFLA.

\subsubsection{Prioridade de Contratação para Empresas Locais ou Regionais}

Com a Lei Complementar no 147/2014 ao alterar a Lei Complementar no 123/2006, apresentou-se uma nova possibilidade para a administração no que se refere à preferência na contratação de MPEs locais e/ou regionais em seus processos licitatórios. Passou a prever a prioridade de contratação para as MPEs sediadas local ou regionalmente, até o limite de $10 \%$ (dez por cento) do melhor preço válido. Nessa perspectiva, nos casos em que a empresa primeira colocada não for micro ou pequena, a MPE sediada local ou regionalmente melhor classificada poderá apresentar proposta de preço inferior àquela considerada vencedora da licitação, situação em que será adjudicado o objeto em seu favor.

O Decreto $n^{\circ} 8.538 / 2015$ esclareceu algumas questões para as quais a Lei Complementar $n^{o} 147 / 2014$ foi vaga. Considera que o âmbito local se refere aos limites geográficos do município onde será executado o objeto da contratação e que o âmbito regional se refere aos limites geográficos do estado ou da região metropolitana, que podem envolver mesorregiões ou microrregiões, conforme definido pelo Instituto Brasileiro de Geografia e Estatística (IBGE).

Para verificar o percentual de MPEs locais e regionais vencedoras nos certames da UFLA, essas foram separadas em dois grupos, conforme suas origens: 1) locais e regionais e 2) outras regiões. Assim, foi possível verificar se houve variação no percentual de MPEs locais e regionais vencedoras durante o período selecionado para o estudo.

Seguindo a definição dada pelo Decreto $n^{\circ}$ 8.538/2015 sobre a delimitação geográfica para empresas locais e regionais, consideraram-se MPEs locais aquelas com sede no município de Lavras-MG e as regionais aquelas com sede nos municípios que compõem a microrregião de Lavras, conforme divisão estabelecida pelo Instituto Brasileiro de Geografia e Estatística (IBGE). A microrregião em questão é composta pelos seguintes municípios: Carrancas, Ijaci, Ingaí, Itumirim, Itutinga, Lavras, Luminárias, Nepomuceno e Ribeirão Vermelho.

No gráfico 4, mostra-se a distribuição do percentual de MPEs vencedoras nos pregões da UFLA entre os anos de 2012 e 2015, segundo suas localidades de origem. 
Gráfico 4 - Origem das empresas vencedoras nos certames da UFLA no período de 2012 a 2015.

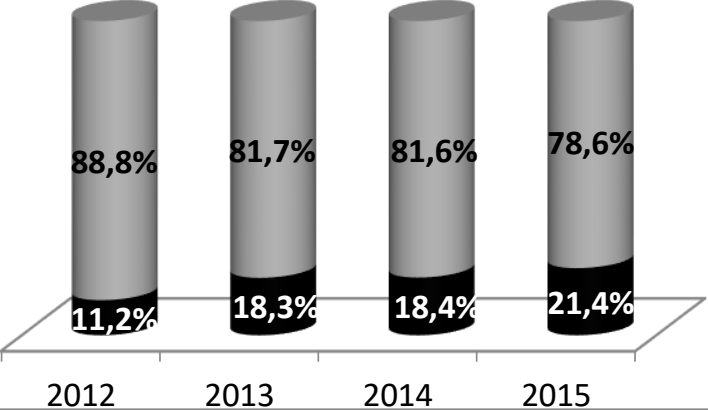

MPEs de outras localidades

MPEs Locais e Regionais

Fonte: Dados da pesquisa (2016).

De acordo com o Gráfico 4, o primeiro ano da série em análise, 2012, foi o ano em que houve menor percentual de MPEs locais e regionais vencedoras nos pregões da UFLA. Nos anos de 2013 e 2014, houve aumento percentual de MPEs locais e regionais, porém, este se manteve na mesma proporção durante os dois anos. No ano de 2015 , constata-se um aumento no percentual de MPEs locais e regionais vencedoras. Não foi constatada, entretanto, nas atas dos pregões analisados, a adoção por parte da Diretoria de Gestão de Materiais da UFLA do benefício que prevê a prioridade de contratação para as MPEs sediadas local ou regionalmente.

É fato que existe um mercado potencial para a atuação de MPEs locais e regionais, o que se vislumbra, a partir do número de MPEs de outras regiões vencedoras nos pregões, no período do estudo, que foi, em média, quatro vezes maior que o número de MPEs locais e regionais. Considerando que um dos objetivos da Lei Complementar $\mathrm{n}^{\circ}$ 123/2006 é promover o desenvolvimento econômico e social no âmbito local e regional, a reflexão que se coloca é se não seria oportuno à administração inserir nos seus trâmites a possibilidade apresentada pela Lei.

Para Frossard e Câmara (2010), as compras públicas não somente podem exercer a função de dotar a administração pública de bens necessários para a execução de políticas públicas, mas podem também apoiar ou estimular segmentos vulneráveis ou estratégicos da sociedade, ser instrumento de geração de emprego e renda e de desenvolvimento regional. Para os autores, deve-se ir além da dimensão econômica, avançando no sentido da finalidade da ação governamental.

O SEBRAE (2014) defende que as MPEs são uma forma objetiva e direta de acesso à mão de obra local e de oferta de produtos locais. Ou seja, beneficiar as MPEs em seus editais de licitação é também uma decisão que contribui para o desenvolvimento nacional sustentável.

\section{Considerações Finais}

Esse estudo foi conduzido com o objetivo de analisar os pregões eletrônicos da Universidade Federal de Lavras (UFLA) entre os anos de 2012 a 2015, a fim de descrever como ocorreu na prática, a aplicação do tratamento diferenciado às MPEs.

O estudo evidenciou que a adoção de muitos dos critérios que imprimem tratamento diferenciado às MPEs, por parte da UFLA, ocorreu após a publicação da Lei Complementar $\mathbf{n}^{\circ}$ 147/2014 ou, em alguns casos, com maior regularidade, após o Decreto $\mathrm{n}^{\mathrm{o}}$ 8.538/2015 que a regulamentou, apesar de já haver previsão na Lei Complementar $n^{\circ} 123 / 2006$ para que tal possibilidade fosse aplicada pela administração discricionariamente. As entrevistas realizadas 
confirmaram que a aplicação habitual dos benefícios da Lei tem se restringido às disposições para as quais há determinação de obrigatoriedade.

A partir do momento em que se considerar a possibilidade de utilizar-se de tal política pública para estimular o desenvolvimento regional, a administração pública, ciente dessa prerrogativa, pode criar condições que favoreçam a aplicação da Lei. Os pregoeiros entrevistados foram unânimes em reconhecer o fomento ao desenvolvimento e a competitividade como umas das vantagens da aplicação da Lei Complementar $n^{\circ}$ 123/2006. Tal posicionamento, porém, depende da existência de um fluxo interno, no qual, servidores e sistemas informacionais estejam preparados para que a aplicação dos critérios da Lei ocorra sem causar inconvenientes à administração.

Como pontos críticos da aplicação da legislação, evidenciou-se a falta de adaptação dos sistemas de informação para operacionalização das mudanças e uma preocupação em não conseguir alcançar o objetivo da Diretoria de Gestão de Materiais que é a efetiva aquisição de bens. $\mathrm{O}$ insucesso na aquisição dos bens está relacionado a pagar, em alguns casos, valores mais altos, adquirir itens de baixa qualidade ou não conseguir adquiri-los em função do não atendimento ao valor de referência ou às especificações exigidas.

A constatação do considerável aumento no número de itens não adquiridos nos pregões ocorridos nos anos de 2014 e 2015, em função do não atendimento aos valores de referência utilizados, foi o ponto crítico apontado pelo estudo. A partir do delineamento do fluxo do processo licitatório, apontou-se a necessidade de aperfeiçoar as etapas do processo que se referem à orientação, execução e aprovação das pesquisas de preço. Tais pesquisas são a origem dos valores utilizados como referência para compra e a sugestão de aperfeiçoá-las surge como uma alternativa para amenizar as chances de insucesso das aquisições.

Os resultados do estudo demonstraram ser salutar que haja uma conciliação entre os interesses da administração e o atendimento às exigências legais. Aplicar a legislação que oferece tratamento diferenciado às MPEs não necessariamente levará a administração a pagar valores mais altos em seus processos licitatórios, porém ciente em atender aos demais objetivos da Lei, que se referem ao fomento aos pequenos negócios e ao desenvolvimento local e regional, cabe aos órgãos públicos estruturarem seus processos licitatórios a fim de alcançarem sucesso na aquisição dos bens. $\mathrm{O}$ atendimento aos critérios da Lei implica em disposição da administração para sobrepor o incentivo às MPEs a outros efeitos que sua aplicação possa desencadear, o que inclui trabalhar com valores de referência que sejam mais apropriados aos processos em que haja a exclusividade para as MPEs.

Oferecer um direcionamento para a administração repensar seu processo licitatório de maneira a atender aos preceitos da Lei, e concomitantemente diminuir as chances de insucesso na aquisição de bens é o que propôs a intervenção resultante desse estudo.

Como limitação do estudo, aponta-se o reduzido tempo de análise do tratamento das MPEs posteriormente às alterações ocorridas na Lei, tendo em vista que a regulamentação ocorreu em outubro de 2015 e muitos dos critérios somente foram aplicados após essa data.

Como sugestão para outros trabalhos, indica-se a possibilidade de ampliar, com o passar dos anos, o período de análise. O estudo do tema é cabível em qualquer órgão público que realize processos licitatórios e os resultados possibilitarão conhecer o panorama geral relativo à aplicação do tratamento diferenciado às MPEs em diferentes órgãos e regiões. 


\section{Referências Bibliográficas}

AGÊNCIA BRASILEIRA DE DESENVOLVIMENTO INDUSTRIAL. Relatório de acompanhamento do Plano Brasil Maior. Brasília, DF, 2014. Disponível em: <http://www.brasilmaior.mdic.gov.br/>. Acesso em: 18 fev. 2016.

BAPTISTA, M. N.; CAMPOS, D. C. Metodologias de pesquisa em ciências: análises quantitativa e qualitativa. Rio de Janeiro: LTC, 2007.

BRASIL. Constituição (1988). Constituição da Republica Federativa do Brasil. Brasília, DF: Senado Federal, 1988.

Decreto $\mathbf{n}^{\mathbf{0}} \mathbf{8 . 5 3 8}$, de 6 de outubro de 2015. Regulamenta o tratamento favorecido, diferenciado e simplificado para as microempresas, empresas de pequeno porte, agricultores familiares, produtores rurais pessoa física, microempreendedores individuais e sociedades cooperativas de consumo nas contratações públicas de bens, serviços e obras no âmbito da administração pública federal. Brasília, DF, 2015. Disponível em:<http://www.planalto.gov.br/ccivil_03/_ato2015-2018/2015/decreto/d8538.htm>. Acesso em: 10 out. 2016.

Lei $\mathrm{n}^{\circ}$ 8.666, de 21 de junho de 1993. Regulamenta o artigo 37, inciso XXI, da Constituição Federal, institui normas para licitações e contratos da Administração Pública, e dá outras providências. Diário Oficial [da] República Federativa do Brasil, Brasília, DF, 22 jun. 1993. Disponível em: <http://www.planalto.gov.br/ccivil_03/leis/L8666cons.htm>. Acesso em: 10 out. 2016.

Lei $n^{\circ} 10.520$, de 17 de julho de 2002. Institui, no âmbito da União, Estados, Distrito Federal e, nos termos do art. 37, inciso XXI, da Constituição Federal, modalidade de licitação denominada pregão, para aquisição de bens e serviços comuns, e da outras providencias. Diário Oficial [da] Republica Federativa do Brasil, Brasília, DF, 18 jul. 2002. Disponível em: <http://www.planalto.gov.br/ccivil_03/leis/2002/110520.htm>. Acesso em: 10 out. 2016.

Lei Complementar $\mathbf{n}^{\mathbf{0}} \mathbf{1 2 3}$, de 14 de dezembro de 2006. Institui o Estatuto Nacional da Microempresa e da Empresa de Pequeno Porte; altera dispositivos das Leis no8.212 e 8.213, ambas de 24 de julho de 1991, da Consolidação das Leis do Trabalho - CLT, aprovada pelo Decreto-Lei no 5.452, de 1o de maio de 1943, da Lei no 10.189, de 14 de fevereiro de 2001, da Lei Complementar no 63, de 11 de janeiro de 1990; e revoga as Leis no 9.317, de 5 de dezembro de 1996, e 9.841, de 5 de outubro de 1999. Brasília, DF, 2006. Disponível em: <http://www.planalto.gov.br>. Acesso em: $6 \mathrm{dez} .2014$.

Lei Complementar $\mathbf{n}^{\mathbf{0}}$ 147, de 7 de agosto de 2014. Altera a Lei Complementar no 123, de 14 de dezembro de 2006, e as Leis nos 5.889, de 8 de junho de 1973, 11.101, de 9 de fevereiro de 2005, 9.099, de 26 de setembro de 1995, 11.598, de 3 de dezembro de 2007, 8.934, de 18 de novembro de 1994, 10.406, de 10 de janeiro de 2002, e 8.666, de 21 de junho de 1993; e dá outras providências. Brasília, DF, 2014a. Disponível em: 〈http://www.planalto.gov.br〉. Acesso em: 8 dez. 2014.

Ministério do Planejamento, Desenvolvimento e Gestão. Portal de Compras do Governo Federal. Como aplicar os avanços da Lei Complementar 123/2006 na área de Compras Governamentais. Brasília, DF, 2014b. Disponível em: $<\mathrm{http}$ ///www.comprasgovernamentais.gov.br/arquivos/capacitacao/4-como-aplicar-osavancos-da-lei-complementar-123-2006-nas-compras-governamentais.pdf > . Acesso em: 9 dez. 2014. 
CABRAL, S.; REIS, P. R. C.; SAMPAIO, A. H. Determinantes da participação e sucesso das micro e pequenas empresas em compras públicas: uma análise empírica. Revista de Administração, São Paulo, v. 50, n. 4, p. 477-491, 2015.

CÂMARA, L. M.; FROSSARD, L. B. de M. Poder de compras da administração pública federal: novas perspectivas para o debate acadêmico. In: ENCONTRO DE ADMINISTRAÇÃO PÚBLICA E GOVERNANÇA, 4., 2010, Vitória. Anais... Vitória: EnAPG, 2010. p. 2-16.

COMPRASNET. Compras públicas um bom negócio para sua empresa. 2014. Disponível em:

$<$ https://www.comprasgovernamentais.gov.br/arquivos/micro-e-pequenasempresas/compras-publicas-29out2014.pdf>. Acesso em: 7 dez. 2014.

CRESWELL, J. W. Projeto de pesquisa métodos qualitativo, quantitativo e misto. In:

Projeto de pesquisa métodos qualitativo, quantitativo e misto. 3. ed. Porto Alegre: $\overline{\text { Artmed, }}$ 2010. p. 238-265.

GIL, A. C. Métodos e técnicas de pesquisa social. 6. ed. São Paulo: Atlas, 2014.

INSTITUTO BRASILEIRO DE GEOGRAFIA E ESTATÍSTICA. As micro e pequenas empresas comerciais e de serviços no Brasil. Rio de Janeiro, 2003. Disponível em: <http://www.ibge.gov.br/home/estatistica/economia/microempresa/>. Acesso em: 7 dez. 2014. KERLINGER, F. N. Metodologia da pesquisa em ciências sociais: um tratamento conceitual. São Paulo: EPU, 2009.

MEIRELLES, H. L. Direito administrativo brasileiro. 41. ed. atual. São Paulo: Malheiros, 2015.

MELLO, C. A. B. de. Curso de direito administrativo. 32. ed. São Paulo: Malheiros, 2015. OBJECT MANAGEMENT GROUP. Business Process Model and Notation (BPMN) version 2.0.2011. 2011. Disponível em: <http://www.omg.org>. Acesso em: 12 set. 2016.

Desenvolvimento humano, trabalho decente e o futuro dos empreendedores de pequeno porte no Brasil. Brasília, DF: SEBRAE, 2008.

SERVIÇO BRASILEIRO DE APOIO AS MICRO E PEQUENAS EMPRESAS. 6 anos do supersimples: a criação de um ambiente favorável aos pequenos negócios. Brasília, DF:

Terraqua, 2013a.

SERVIÇO BRASILEIRO DE APOIO AS MICRO E PEQUENAS EMPRESAS. Unidade de Políticas Públicas. Inovações introduzidas pela Lei Complementar 147. Brasília, DF, 2014. Disponível em: <http://docplayer.com.br/12989304-Inovacoes-introduzidas-pela-leicomplementar.html>. Acesso em: 25 nov. 2015.

WALES, W. J. et al. Nonlinear effects of entrepreneurial orientation on small firm performance: the moderating role of resource orchestration capabilities. Strategic Entrepreneurship Journal, Chicago, v. 7, n. 2, p. 93-121, 2013. 